Purdue University Purdue e-Pubs

$11-2012$

\title{
Liquid-Flooded Compression and Expansion in Scroll Machines - Part I: Model Development
}

Ian Bell

Purdue University, ian.h.bell@gmail.com

Vincent Lemort

University of Liege, vincent.lemort@ulg.ac.be

Eckhard Groll

Purdue University,groll@purdue.edu

James E. Braun

Purdue University - Main Campus, jbraun@purdue.edu

Galen King

Purdue University, kinggb@purdue.edu

See next page for additional authors

Follow this and additional works at: http://docs.lib.purdue.edu/herrick

Bell, Ian; Lemort, Vincent; Groll, Eckhard; Braun, James E.; King, Galen; and Horton, W. Travis, "Liquid-Flooded Compression and Expansion in Scroll Machines - Part I: Model Development" (2012). Publications of the Ray W. Herrick Laboratories. Paper 64. http://docs.lib.purdue.edu/herrick/64

This document has been made available through Purdue e-Pubs, a service of the Purdue University Libraries. Please contact epubs@purdue.edu for additional information. 
Authors

Ian Bell, Vincent Lemort, Eckhard Groll, James E. Braun, Galen King, and W. Travis Horton 


\title{
Liquid-Flooded Compression and Expansion in Scroll Machines - Part I: Model Development
}

\author{
Ian H. Bell ${ }^{\mathrm{a}, *}$, Vincent Lemort ${ }^{\mathrm{b}}$, Eckhard A. Groll ${ }^{\mathrm{a}}$, James E. Braun ${ }^{\mathrm{a}}$, Galen B. King ${ }^{\mathrm{a}}$, W. Travis Horton ${ }^{\mathrm{a}}$ \\ ${ }^{a}$ Purdue University Department of Mechanical Engineering, 140 S. Martin Jischke Drive, West Lafayette, IN, 47906 \\ ${ }^{b}$ University of Liège, Aerospace and Mechanical Engineering, Liège, Belgium
}

\begin{abstract}
A detailed mechanistic model has been developed for scroll compressors and scroll expanders with liquid flooding for application to the Liquid Flooded Ericsson Cycle. This model is based on the integration of a set of differential equations that arise from the conservation laws. The impact of the flooding liquid on the working process is also included through mixture properties as well as treatment of two-phase flow pressure drop. With the working process known, it is then possible to solve for the compressor power, total mass flow rate and other model outputs. The fine level of detail in the model allows for the investigation of the impact of design changes to the scroll machines. This model can also be readily extended to allow for the analysis of liquid flooded vapor compression refrigeration.
\end{abstract}

Key words:

scroll compressors, scroll expanders, liquid flooding, numerical modeling, isothermal compression, high efficiency

\section{Introduction}

In the past a number of researchers have investigated oil flooded compression in screw compressors (Wu and Jin, 1988; Tang and Fleming, 1992; Stosic et al., 1990, 1988; Singh and Patel, 1984; Li and Jin, 2004; Wu et al., 2004; Fujiwara and Osada, 1995; Blaise and Dutto, 1988; Bein and Hamilton, 1982) which are geometrically related to a scroll compressor and for which many similar physical effects can be noted. The motivation for oil-flooding in screw compressors is two-fold; to decrease the discharge temperature of the compressor as well as to improve the sealing along the long leakage paths. Blaise \& Dutto (1988) investigated the impact of oil flooding and found that it increased the volumetric efficiency monotonically and there was an oil flow rate that maximized the isentropic efficiency. Stosic et al. (1988) investigated flooded screw compressors as well and found the same trends. In addition, they found that the volumetric efficiency increased with an increase in oil viscosity. Stosic et al. (1990) found an optimal value for the mass ratio of oil to gas which minimized the discharge temperature and therefore maximized the efficiency. Li and Jin (2004) found an optimal flooding rate dependent on the oil injection temperature.

Similar experimental studies with oil flooding have been carried out on scroll compressors. Sakuda et al. (2001) in-

\footnotetext{
* Corresponding Author

Email addresses: ian.h.bell@gmail.com (Ian H. Bell) vincent.lemort@ulg.ac.be (Vincent Lemort), groll@purdue.edu (Eckhard A. Groll), jbraun@purdue.edu (James E. Braun), kinggb@purdue.edu (Galen B. King), wthorton@purdue.edu (W. Travis Horton)
}

vestigated scroll compressor oil flow rates, and they found that the cycle efficiency always decreased with increasing oil flow rates. Hiwata et al. (2002) investigated the injection of oil into a $\mathrm{CO}_{2}$ scroll compressor and found that there was always an optimal oil flooding rate which maximized the efficiency of the compressor. This optimal oil flooding rate ranged between 6 and $15 \%$ by mass. Spool compressors have also been tested with oil flooding with promising preliminary results (Kemp et al., 2010). The overall isentropic and volumetric efficiencies were found to increase monotonically with oil injection rate for oil injection rates up to $30 \%$ by mass.

The model developed in this paper is an extension of earlier models that were developed by Halm (1997) and Chen $(2002 ; 2004)$ for scroll compressors that did not incorporate liquid flooding. The important contribution of this paper is the treatment of a mixture of gas and large mass fraction of oil. The first step in the analysis of a scroll compressor or expander is the calculation of the scroll machine chamber volumes as a function of the crank angle. In addition the derivatives of scroll chamber volumes with respect to the crank angle are necessary for mass and energy balances. The geometric model also predicts the evolution of the axial and radial leakage gaps, as well as the heat transfer areas.

The working processes of oil-flooded compressors and expanders are modeled by numerically solving the governing equations of conservation of mass, oil mass, and energy for each chamber within the scroll compressor or expander. These differential equations take into account boundary work, mass flows, and heat exchange, and their solution yields the evolution of the mixture pressure and

April 6, 2012 
temperature in all of the chambers over one revolution. An overall model for each machine couples the solution for the compression/expansion process to an overall network energy flow analysis that includes a lumped mass element for which steady-state energy balance is established. The global model computes the total mass flow rate displaced by the machine, the average discharge temperature and enthalpy, the shaft power and the efficiencies of the machine.

Experimental validation of these models has been conducted and is presented in a separate paper (Bell et al., 2011b). In addition, a third paper covers the optimization of scroll compressors for large amounts of oil injection (Bell et al., 2011a). In the current study, the same automotive open-drive scroll compressor is used as both the compressor and expander. Thus, at a given crank angle, the volumes of the working chambers for both compressor and expander will be the same but the definitions of the chambers are different since the direction of rotation is opposite in compressor and expander modes.

\section{Volume Calculations}

The concept of the scroll compressor was introduced by Creux (1905). Expressions for a scroll machine's chamber volumes as a function of crank angle have been previously derived, and modern treatments of the scroll machine's geometry have been proposed by Yanagisawa (1990), Bush (1992; 1994), Halm (1997) Wang (2005) and Blunier (2009; 2006). It is possible to use these expressions to model the evolution of the volume in the suction and compression chambers of the compressor, but the discharge region of the compressor (suction region of the expander) is more challenging to handle due to its complex geometry. Previous investigators modeled compressors that used simple tangent arcs to close the involute pairs that form each scroll in the discharge region. The scroll machine currently under investigation uses a set of two arcs and a line to close the involute pair as seen in Figure 1. Numerical integration can be used to calculate the volumes in the discharge region, or analytic solutions are available for the discharge chamber geometry (Bell, 2011).

One of the critical parameters in matching compressors and expanders to their application is the built-in volume ratio. The volume ratio is given by the displacement volume of the compressor's suction chamber divided by the volume of the compression chamber right at the point where it is about to discharge into the discharge region. A built-in volume ratio that is well matched to the operating pressure ratio will minimize under- or over- compression and expansion losses.

\subsection{Identified Scroll Parameters}

An optical scan of the compressor's orbiting scroll was obtained with a flatbed document scanner and an involute curve was fit to the points obtained from the scan based

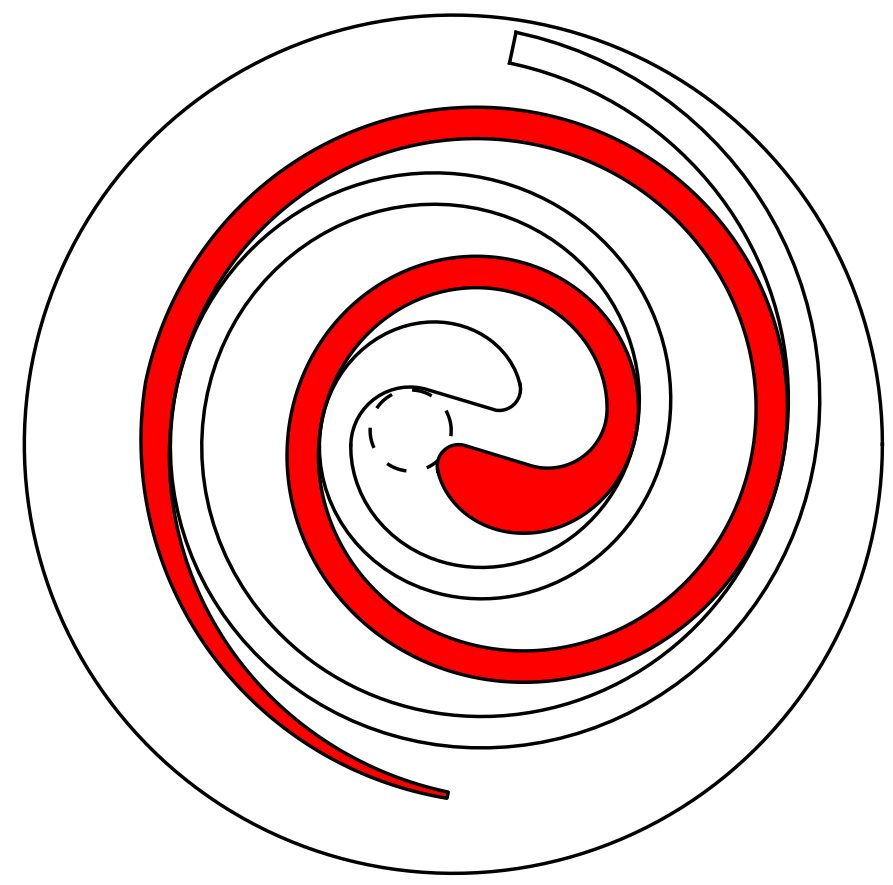

Figure 1: Scroll machine geometry

on the measured scroll wall thickness and the displacement volume in compressor mode. The thickness of the scroll is defined by $t=r_{b}\left(\phi_{i 0}-\phi_{o 0}\right)$, and the manufacturer specifies that the displacement volume of the compressor is 104.8 $\mathrm{cm}^{3}$ in compressor mode. Using the scan, the measured thickness, and the known displacement volume, the scroll geometric parameters can be obtained, the values of which can be found in Table 1, and the scan of the scroll with overlaid curves is shown in Figure 2. Furthermore, the geometry of the curves which form the discharge chamber in compressor mode was fit to the points selected from the optical scan. The definitions of the geometric parameters follow those of Halm (1997), though re-derivation of the volume expressions are required since the involute angles do not take the special values of $\pi / 2$ and 0 for the inner and outer involute initial angles respectively. The improved geometric analysis in Wang et al. (2005) can be used with reasonable accuracy, but the comprehensive geometric model of Bell (2011) is recommended.

\begin{tabular}{cl} 
Table 1: Scroll Geometric Parameters \\
\cline { 2 - 2 } $\mathrm{r}_{b}[\mathrm{~mm}]$ & 3.522 \\
$\mathrm{r}_{o}[\mathrm{~mm}]$ & 6.405 \\
$\phi_{i 0}[\mathrm{rad}]$ & 0.1983 \\
$\phi_{\text {is }}[\mathrm{rad}]$ & 4.7 \\
$\phi_{\text {ie }}[\mathrm{rad}]$ & 15.5 \\
$\phi_{o 0}[\mathrm{rad}]$ & -1.125 \\
$\phi_{\text {os }}[\mathrm{rad}]$ & 1.8 \\
$\phi_{o e}[\mathrm{rad}]$ & 15.5 \\
$h_{s}[\mathrm{~mm}]$ & 32.89 \\
\hline \hline
\end{tabular}




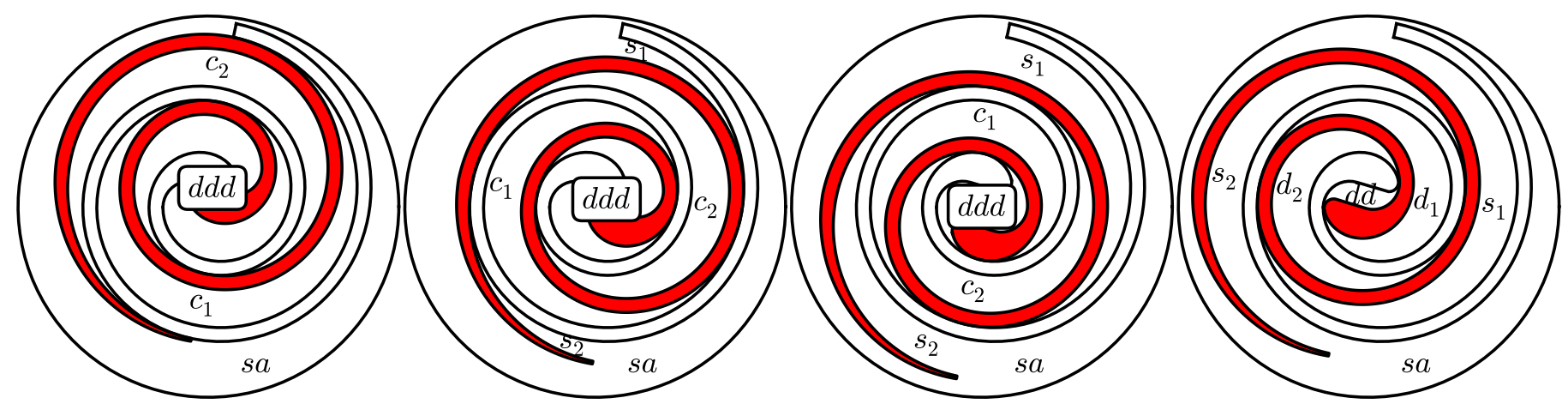

Figure 5: Scroll compressor pockets over the course of one rotation
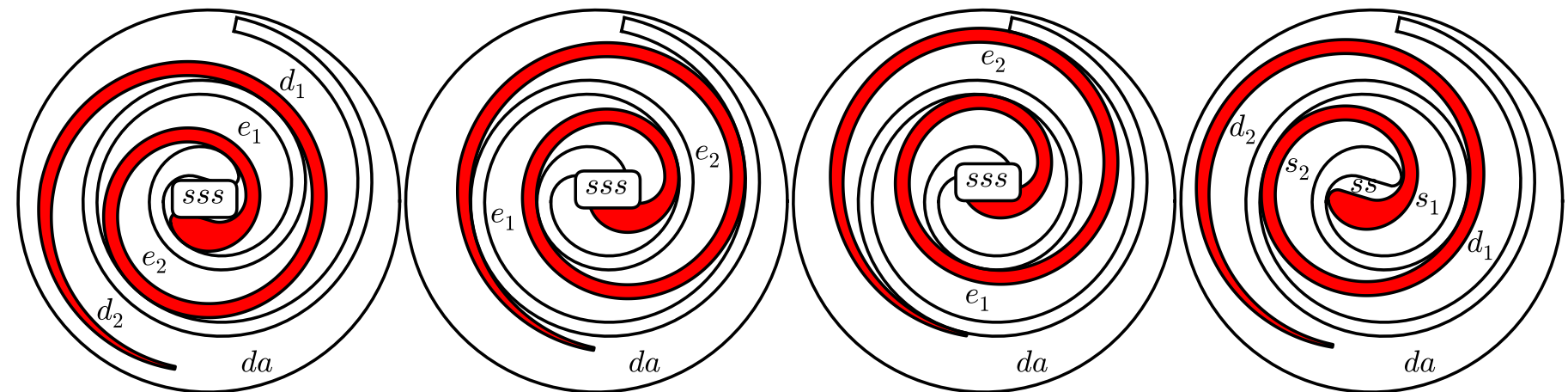

Figure 6: Scroll expander pockets over the course of one rotation

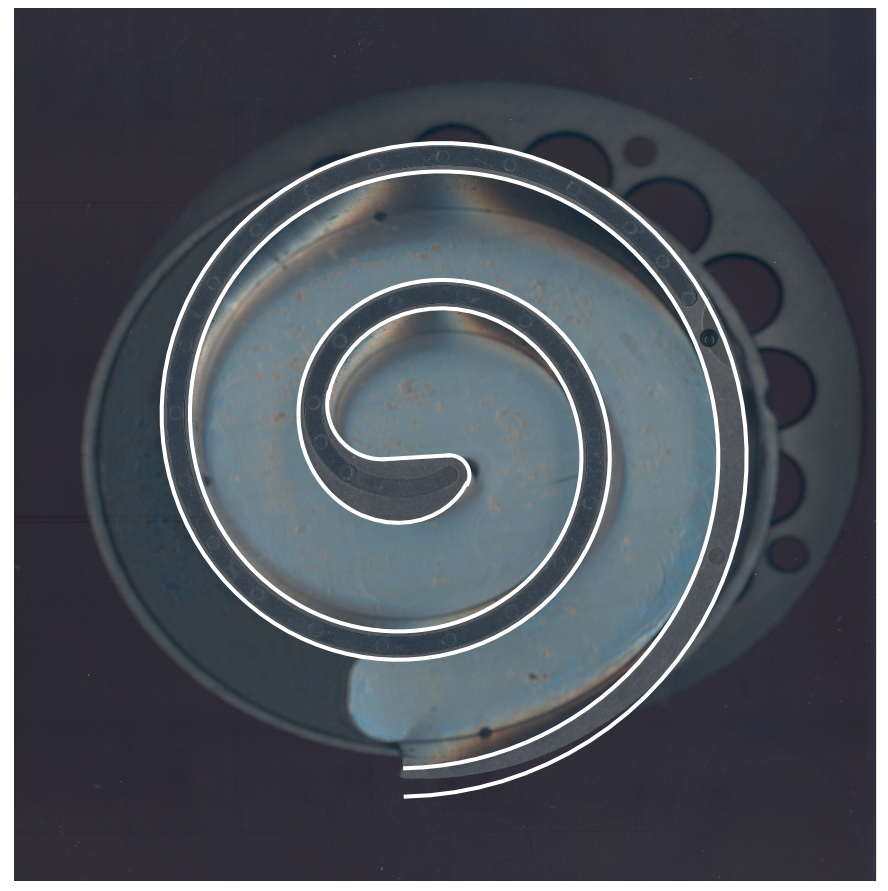

Figure 2: Optical scan of orbiting scroll with overlaid curves obtained for scroll geometry

Figures 3 and 4 show the volumes of the chambers of the scroll compressor and scroll expander respectively over the course of one rotation, and Figures 5 and 6 show how the

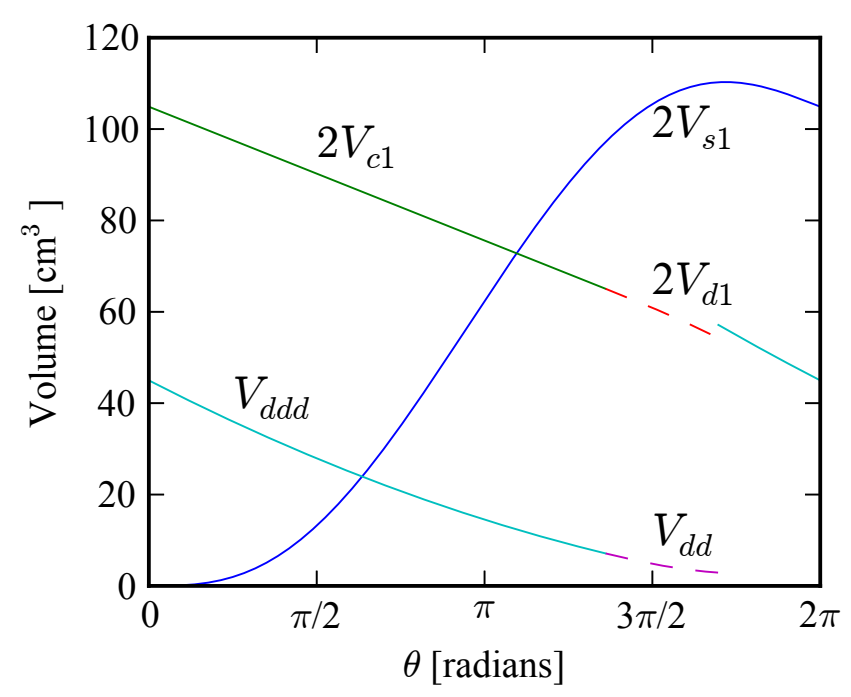

Figure 3: Volumes of scroll compressor pockets over the course of one rotation

chamber definitions change over one rotation. The subscripts 1 and 2 correspond to the two parallel flow paths. The volumes of the suction and compression chambers for both paths are equivalent. In compressor mode, the suction chamber $s_{1}$ and $s_{2}$ begin to open and allow refrigerant and oil mixture to enter into the suction pocket. After one full crankshaft revolution of $2 \pi$ radians or 360 degrees, the 


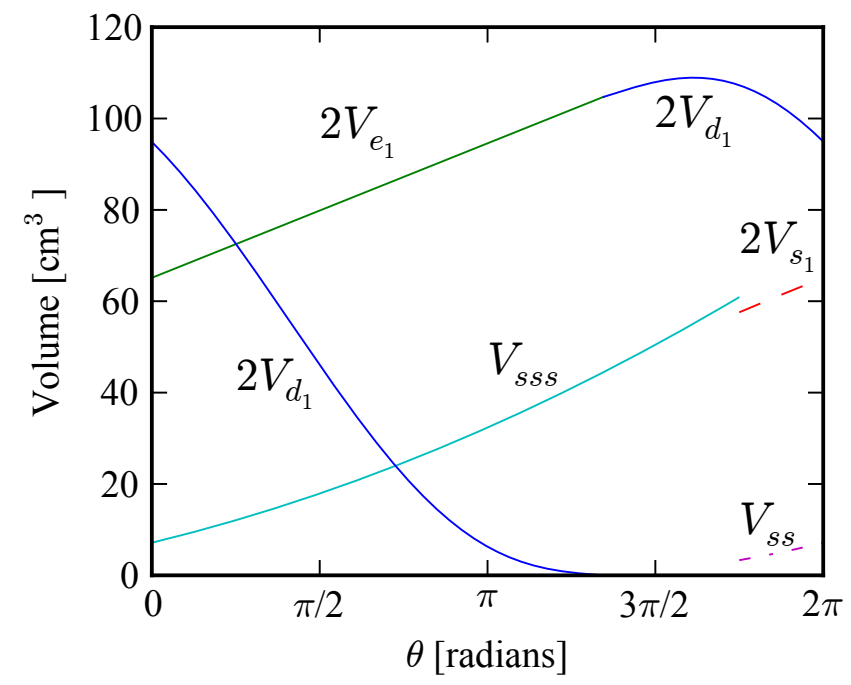

Figure 4: Volumes of scroll expander pockets over the course of one rotation

suction chambers $s_{1}$ and $s_{2}$ are closed off and they become compression chambers $c_{1}$ and $c_{2}$ respectively. After reaching the discharge angle, the compression chambers begin to open to the discharge region and are given the titles of $d_{1}$ and $d_{2}$ respectively. These discharge chambers begin to equalize in pressure with the remaining volume in the discharge region which is denoted as the $d d$ chamber. As the rotation progresses, chambers $d_{1}, d_{2}$, and $d d$ are merged together into a chamber called $d d d$ once they have equalized in pressure. The chamber $s a$ is the chamber formed between the outer surface of the scroll wraps and the inner wall of the compressor shell.

In expander mode, the suction chamber, which is in communication with the suction port (discharge port in compressor mode) is named chamber sss. This chamber can be fictitiously divided into chambers $s s, s_{1}$ and $s_{2}$. It is useful to impose this subdivision when the different subchambers are in communication only by small gaps (which can be determined from the orbiting angle). The small gaps lead to significant pressure differences between all of suction region chambers. Such a situation is depicted in the last frame of Figure 6 where chamber ss is in communication with chamber $s_{1}$ and chamber $s_{2}$ through the small opening between the tip of each scroll and the inner involute of the opposite scroll. Chamber $e_{1}$ and chamber $e_{2}$ are the expansion chambers that develop from chambers $s_{1}$ and $s_{2}$ respectively. Chambers $d_{1}$ and $d_{2}$ are the discharge chambers that develop, at the discharge angle, from the expansion chambers $e_{1}$ and $e_{2}$ respectively. The chamber $d a$ is the chamber formed between the outer surface of the scroll wraps and the inner wall of the compressor shell.

\section{Mixture Properties}

In order to integrate the mixture of oil and gas in the thermodynamic model, it is necessary to derive mixture properties which allow the mixture to be treated as a pseudo-pure fluid, greatly simplifying the analysis required. In order to apply a simple ideal mixture model, it is assumed that the oil and gas vapor are at the same temperature and pressure throughout the compression/ expansion process. While the assumption of mechanical equilibrium is valid, the validity of the assumption of thermal equilibrium is more unclear. Experimental results from the companion paper (Bell et al., 2011b) show that the temperatures measured at the outlet of the compressor are similar to the temperatures measured approximately one meter downstream, suggesting thermal equilibrium is maintained inside the compression process. On the other hand, the temperatures measured at the outlet of the expander are quite different than those measured downstream. This problem is further discussed in the companion paper (Bell et al., 2011b).

For a homogenous two-phase mixture with equal oil and gas velocities, the mixture specific volume is given by

$$
v_{m}=x_{l} v_{l}+\left(1-x_{l}\right) v_{g}
$$

where $x_{l}$ is the mass fraction of the flooding liquid which yields an oil mass fraction weighted average of the properties of pure oil and gas properties. The parameter $x_{l}$ is defined by

$$
x_{l}=\frac{\dot{m}_{l}}{\dot{m}_{g}+\dot{m}_{l}}
$$

and the gas mass fraction is defined by $x_{g}=1-x_{l}$. The mixture specific internal energy $u_{m}$, mixture specific enthalpy $h_{m}$, mixture specific entropy $s_{m}$, and mixture constant pressure specific heat $c_{p, m}$ are also defined as an oil-mass-fraction weighted average of the pure phase properties.

The homogeneous void fraction is the fraction of the mixture's volume that is gas with the assumption of equal phase velocities due to the fact that the two-phase mixture is constrained by the scroll wraps during the working process. The void fraction $\alpha$ is given by

$$
\alpha=\frac{x_{g} v_{g}}{x_{l} v_{l}+x_{g} v_{g}}
$$

The mixture thermal conductivity can be defined as a parallel conduction through liquid and gas, and is therefore defined as the void-fraction weighted average of the liquid and vapor conductivities:

$$
k_{m}=(1-\alpha) k_{l}+\alpha k_{g}
$$

and the mixture viscosity is obtained based on the model presented by McAdams (1942), which achieves the correct pure gas and pure liquid viscosities for $x_{l}=0$ and $x_{l}=1$ respectively:

$$
\mu_{m}=\left(\frac{x_{l}}{\mu_{l}}+\frac{x_{g}}{\mu_{g}}\right)^{-1}=\frac{\mu_{l} \mu_{g}}{\mu_{g} x_{l}+\mu_{l} x_{g}}
$$




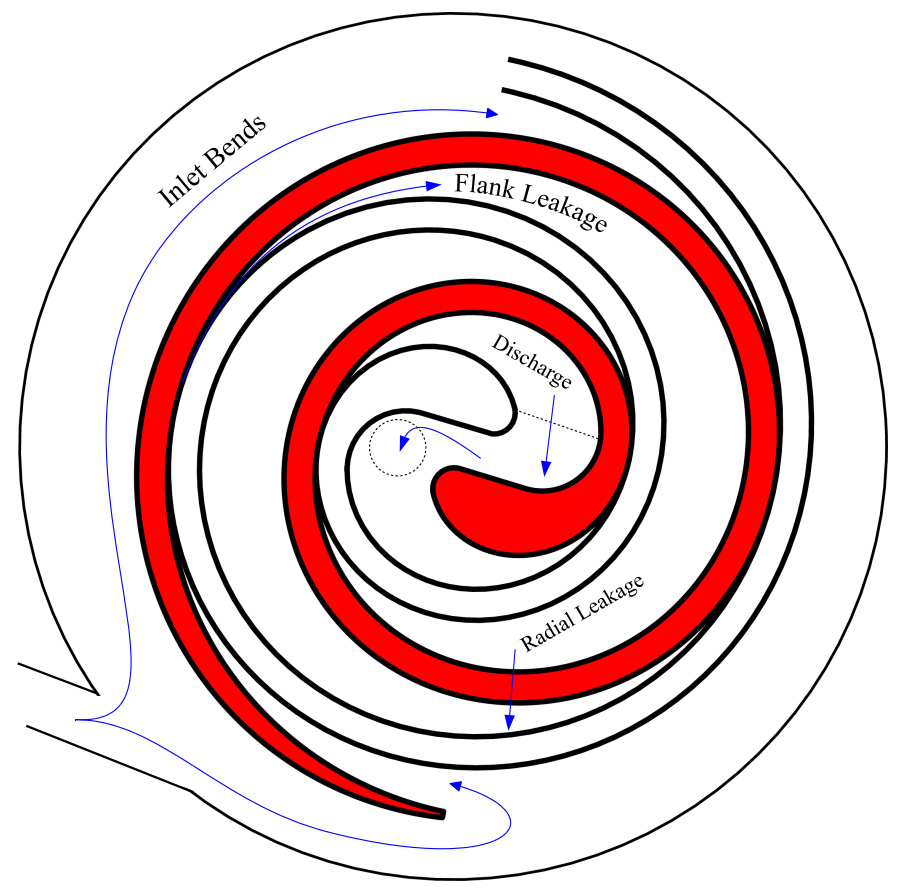

Figure 7: Flows in the scroll compressor

The mixture Prandtl and Reynolds Numbers are based on mixture properties and are given by

$$
\begin{gathered}
\operatorname{Pr}_{m}=\frac{\mu_{m} c_{p, m}}{k_{m}} \\
\operatorname{Re}_{D_{h}}=\frac{4 \dot{m}}{\pi \mu_{m} D_{h}}=\frac{\rho_{m} U_{m} D_{h}}{\mu_{m}}
\end{gathered}
$$

\section{Mass Flow Models}

In flooded scroll compressors and expanders, there are a number of different flow paths, encompassing the primary flow path from inlet to outlet, as well as well as the leakage flow paths. The flows in the primary flow path are significantly different than those of the leakages, and thus, different models must be used for each category of flow. The selection of the flow models is presented here, and the description of the models follows.

As the flow enters into the compressor shell, it splits into two flow paths and these streams change direction to enter the suction pockets, as seen in Figure 7. In the expander, the flows merge together as they exit the expander shell, but they experience a similar change in flow direction. Two models have been applied for this flow path, a flow through pipe bends model and a two-phase nozzle flow with a fictitious area correction coefficient. Both models were found to yield similar results, and the simpler fictitious area correction coefficient method was ultimately selected.

After the flow of gas-liquid has entered into the suction chambers the next flow is from the $d_{1}$ and $d_{2}$ chambers to the $d d$ chamber. As the geometry of this flow path is similar to that of a convergent nozzle, the flow is treated as that through a convergent nozzle with adiabatic, compressible two-phase flow. For the short time until pressure equilibrium occurs in the discharge region, the flow between the $d_{1}$ and $d_{2}$ chambers is very much like a converging nozzle. This configuration can be seen in the last frame of Figure 5. The same analysis is used in expander mode.

For the leakage paths, the commonly-used assumption that the flow path is frictionless is inaccurate, even in the case that the leakages are entirely filled with gas. This is due to the relatively long lengths of the leakage paths. For example, a typical radial leakage path might be $10 \mu \mathrm{m}$ in height and $5 \mathrm{~mm}$ in length, which yields a length to height ratio of 500. Thus, the leakage path is much more like frictional flow between parallel plates than flow through an infinitely-thin nozzle.

\subsection{Two-Phase Nozzle Flow}

Numerous models are available to describe the flow of a two-phase mixture of liquid and gas through nozzles, orifices, and other flow elements. With respect to the pressure difference characteristic of suction and discharge flows, the model should account for the compressibility of the gas. Based on momentum conservation, Chisholm (1983) derived an equation for calculating the mass flow rate of a compressible flow of gas-liquid mixtures through an orifice. According to this equation, for a flow going from a chamber at pressure $p_{\text {high }}$ to another at pressure $p_{\text {low }}$, the mass flow rate is given by:

$$
\dot{m}=C_{d} A_{e} \sqrt{\frac{2 \int_{p_{\text {low }}}^{p_{\text {high }}} v_{e} d p}{v_{e, l o w}^{2}-\sigma v_{e, \text { high }}^{2}}}
$$

where $\sigma$ is the ratio of downstream to upstream flow areas. The integral in Eqn. 8 is obtained using numerical integration. Due to the complicated geometry in the scroll machine, there is no analytic form of the area ratio $\sigma$, and the area ratio was selected to be approximately zero for all flow paths. Setting $\sigma$ to zero yields the lowest mass flow rate for a given set of boundary conditions for the flow path.

In the case of flow with liquid entrainment in the gas phase, Chisholm (1983) proposed to calculate the mixture's effective specific volume by a momentum balance on a differential flow element. In the flow entrainment formulation of the effective mixture specific volume, the effective specific volume is given as

$$
v_{e}=\left[x_{g} v_{g}+K_{e}\left(1-x_{g}\right) v_{l}\right]\left[x_{g}+\frac{1-x_{g}}{K_{e}}\right]
$$

and the effective slip ratio is given by

$$
K_{e}=\left[\psi+\frac{(1-\psi)^{2}}{K-\psi}\right]^{-1}
$$

where $\psi$ is the fraction of liquid that travels in the gas phase at the gas velocity, and taken to be equal to 0.4 as 
proposed by Chisholm. The entrainment slip ratio $\mathrm{K}$ is evaluated from

$$
K=\psi+(1-\psi) \sqrt{\frac{1+\psi\left[\left(1-x_{g}\right) / x_{g}\right] v_{l} / v_{g}}{1+\psi\left(1-x_{g}\right) / x_{g}}} \sqrt{\frac{v_{g}}{v_{l}}}
$$

In the case that there is no entrainment $(\psi=0)$ (the oil and gas flow separately but not necessarily at the same velocities), the liquid entrainment model reduces to the separated flow model. In the case that the liquid is fully entrained in the gas phase $(\psi=1)$ and the oil travels at the same velocity as the gas phase, the homogeneous flow model is obtained, and the effective specific volume is given by Equation 1.

The two-phase discharge coefficient $C_{d}$ is obtained by applying the two-phase flow model presented by Morris (1991), which yields a nominal value for $C_{d}$ of 0.77 . The throat area of the nozzle is furthermore multiplied by a fictitious correction term $X_{d}$ in order to compensate for correlation uncertainty and additional flow irreversibilities not captured by the isentropic two-phase model. The effective area is then given by

$$
A_{e}=X_{d} A_{\text {throat }}
$$

As an example of the uncertainty associated with twophase pressure drop measurements, Chisholm (1983) recommends that if flow is disturbed upstream of an elbow with two-phase flow, the pressure drop should be multiplied by 1.6. The flows in the scroll machine are significantly disturbed for all the two-phase flow paths. Thus, it is not surprising that flow correction factors on this order are required. The companion paper discusses the tuning of this area correction parameter more extensively. Figures 8 and 9 show the circuitous paths that the flow needs to traverse to enter or exit the scroll machine working chambers. Each change of direction or area introduces further irreversibilities which are quite difficult to capture, even with state-of-the-art two-phase flow correlations.

\subsection{Frictional Leakage Flow}

The appropriate model for flow through the radial leakages is frictional flow. Here the flow is also assumed to be incompressible. The arc length of a given radial leakage flow path is based on the arc length of the radial leakage for the high pressure side of the scroll and is given by $s_{r}$ and the height of a radial leakage is given by $\delta_{r}$, where the arc length $s_{r}$ is as shown in Figure 10. Thus, the hydraulic diameter of the leakage gap width (neglecting the curvature of the scroll wraps) is

$$
D_{h}=\frac{4 A}{P}=\frac{4 s_{r} \delta_{r}}{2 s_{r}+2 \delta_{r}} \approx 2 \delta_{r}
$$

Similar analysis for the flank leakage shows that the flank leakage hydraulic diameter is also equal to twice the flank leakage gap width. This demonstrates that due to the slender inlet aspect ratio of the leakage, the geometry

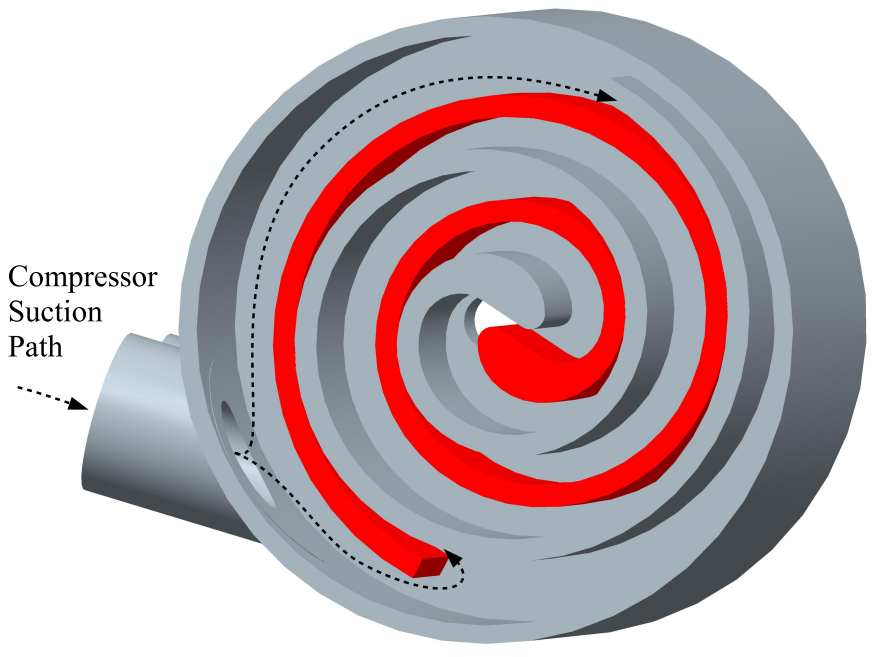

Figure 8: Flows in the suction process of scroll compressor

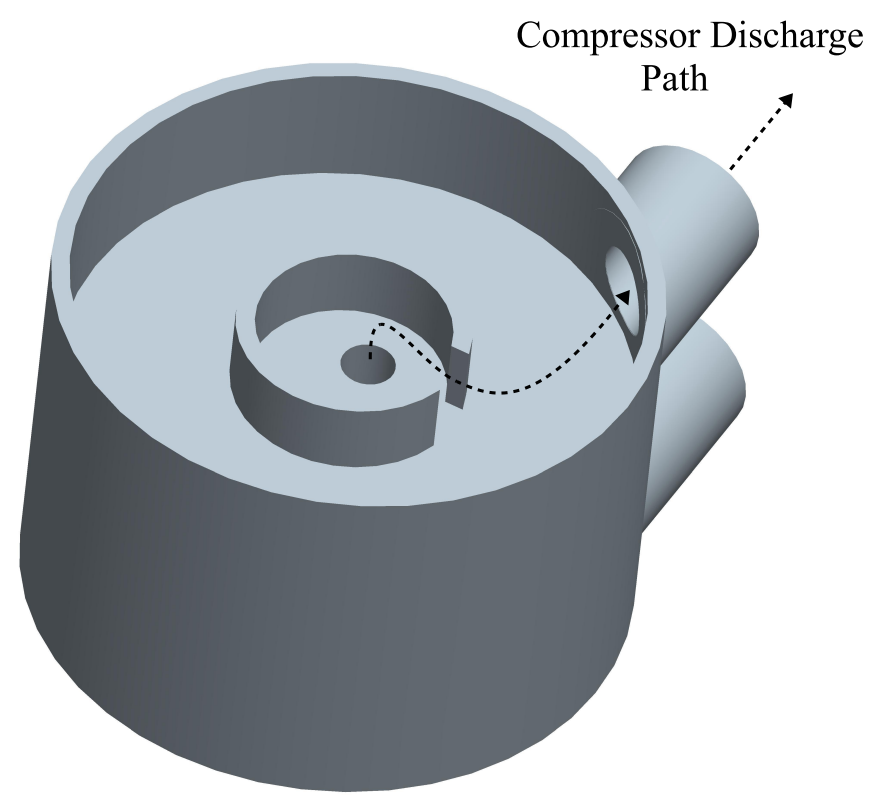

Figure 9: Flows in the discharge process of scroll compressor

is physically similar to that between parallel plates. The Reynolds number for the flow is then given by

$$
\operatorname{Re}_{D_{h}}=\frac{G D_{h}}{\mu_{m}}
$$

The Darcy friction factor expression is given by

$$
f= \begin{cases}64 / \operatorname{Re}_{D_{h}} & \operatorname{Re}_{D_{h}}<1038 \\ 0.35 / \operatorname{Re}_{D_{h}}^{0.25} & \operatorname{Re}_{D_{h}} \geq 1038\end{cases}
$$

where the fully rough turbulent friction factor is obtained from Ishii (1996), and the laminar Reynolds number is that for flow through a rectangular channel. In the transitional Reynolds number regime, the turbulent and laminar Reynolds number curves are extrapolated to intersection in order to ensure that the friction factor curve is monotonic, aiding numerical convergence. The flow is in general 


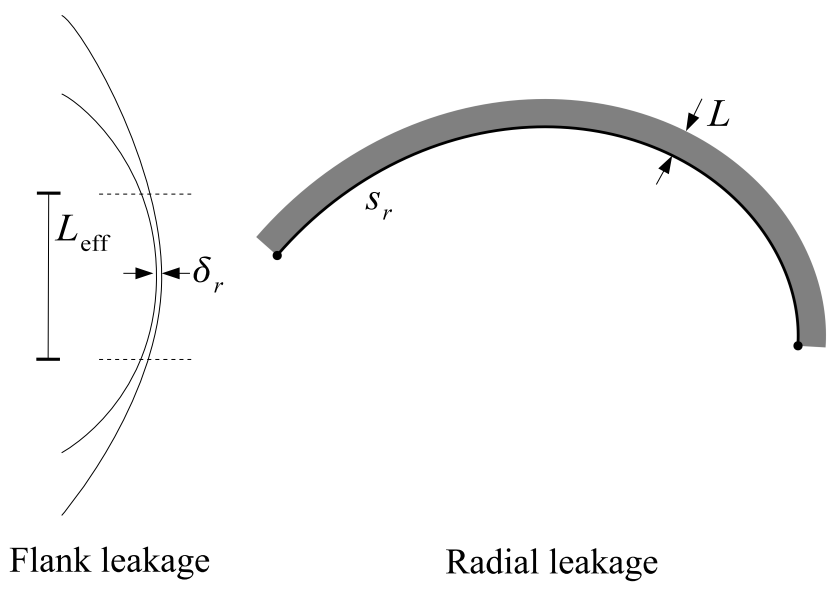

Figure 10: Definition of geometry for leakage paths

laminar due to the small hydraulic diameter. The pressure drop is given by

$$
\Delta p=\frac{f G^{2} L}{2 \rho_{m} D_{h}}
$$

With the frictional factor expressed in the form $f=$ $a \operatorname{Re}_{D_{h}}^{b}$, the mass flux can be directly found by solving

$$
\dot{m}=A G=A\left(\frac{2 \rho_{m} \mu_{m}^{b} \Delta p}{a D_{h}^{b-1} L}\right)^{1 /(b+2)}
$$

For each of the radial leakages, the length of the flow path $L$ is equal to the scroll thickness and the flow area $\mathrm{A}$ is equal to

$$
A=s_{r} \delta_{r}
$$

where the arc length of each radial flow path $s_{r}$ is given from the geometric model. This definition of the area assumes that the flow is in general from the inside of the scroll wrap to the outside of the scroll wrap. For the flank leakages the area is given by

$$
A=h_{s} \delta_{f}
$$

and the effective length $L_{\text {eff }}$ is equal to $2.1 \mathrm{~mm}$. The flank leakage effective length is found by equating the constantflow-area pressure drop from Eqn. 16 to that proposed by Ishii $(1996 ; 2008)$ for the flank leakage with variable-flowarea and obtaining the average value over one rotation. For the flank leakage, the length to minimum height ratio is greater than 150, suggesting that friction should still be considered.

\section{Heat Transfer}

Heat transfer in the scroll machine is complex, and is simplified by grouping the many elements of the compressor and expander into a lumped mass for which steadystate conservation of energy is imposed. For the machines considered in this study, one lumped mass was employed

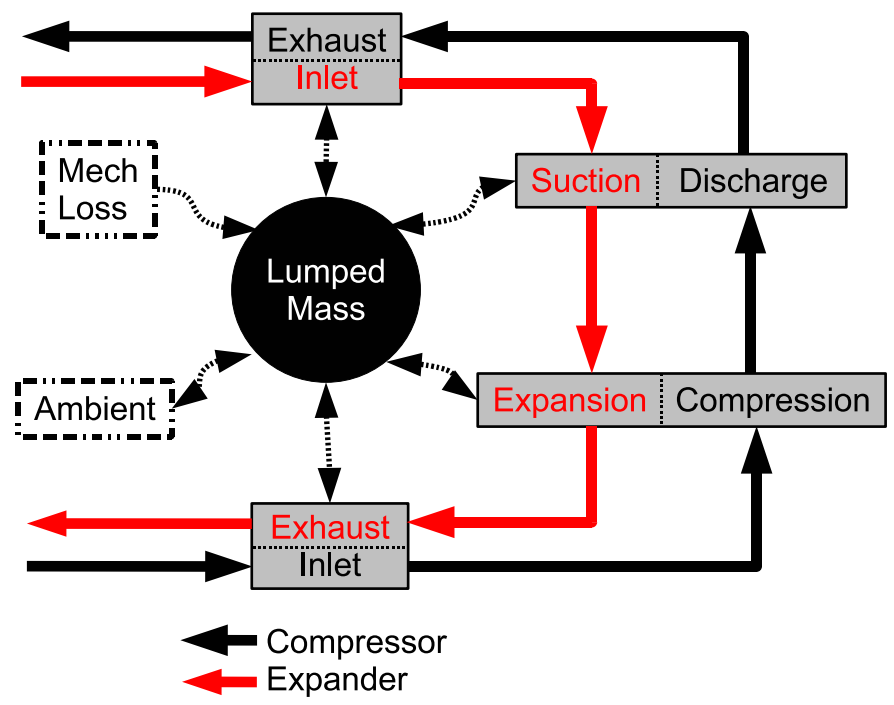

Figure 11: Map of Heat Flows in Scroll Machine

which contains the scrolls and the shell. Relative to conventional vapor-compression compressors, heat transfer for the flooded compression/expansion is less important. This decreased sensitivity to heat transfer is a result of the fact that the addition of oil greatly increases the specific heat of the gas/liquid mixture in the suction chamber which makes the volumetric efficiency less sensitive to heat transfer. In addition, the oil decreases the compressibility of the mixture in the suction pocket, further resulting in less sensitivity to heat input.

Figure 11 shows a schematic of the heat transfer which occurs in the scroll machine. The red line refers to the path of the refrigerant-oil mixture in the expander, and the black line corresponds to that of the compressor. The mechanical losses are added to the lumped mass, and the lump also exchanges heat with the ambient.

\subsection{Inlet and Exhaust Heat Transfer}

The scroll machine under investigation is an open-drive automotive compressor. As the gas enters the machine through the inlet tube shown in Figure 8, the gas-liquid mixture exchanges heat with the shell of the machine, and then the mixture passes into the suction region. For the compressor, the suction region is a channel that allows gas to flow to the opposite side of the compressor and equalize the suction chamber pressures for balanced compression. For the expansion process, the gas flows through the scroll machine in the opposite direction, and thus the inlet for the expander is what would normally be the discharge plenum of the compressor. For both scroll machines, the suction and discharge heat transfer coefficients can be obtained from the classic Dittus-Boelter fully-developed turbulent pipe-flow correlation given by

$$
h_{c}=0.023 \frac{k_{m}}{D_{h}} \operatorname{Re}_{D_{h}}^{0.8} \operatorname{Pr}_{m}^{0.4}
$$


where averaged properties based on the mixture properties are used and the rate of heat transfer can be obtained from the assumption that the tube wall is isothermal and at the lumped temperature. The rate of heat transfer in the inlet and exhaust regions is relatively small due to the small area for heat transfer.

\subsection{Scroll-Gas Heat Transfer}

In the scroll machine, the scrolls are in general at a different temperature than the gas that is in contact with them. As a result, there will be heat transfer between the scrolls and the gas in the chambers. For the compressor, mechanical losses will tend to heat the scrolls resulting generally in heat transfer from the scrolls to the gas, but this will depend on the exact operating conditions. The calculation of the local heat transfer coefficient at the scroll surface is obtained by adjusting the Dittus-Boelter turbulent pipe flow correlation with correction factors for the oscillating nature of the flow and the increase in heat transfer from the spiral shape of the flow path. The adjusted heat transfer coefficient is obtained using correction factors from Tagri (1962) and Jang and Jeong (2006) and is given by

$$
\begin{array}{r}
h_{c}=0.023 \frac{k_{m}}{D_{h}} \operatorname{Re}_{D_{h}}^{0.8} \operatorname{Pr}_{m}^{0.4}\left(1.0+1.77 \frac{D_{h}}{r_{a v g}}\right) \\
\times(1+8.48[1-\exp (-5.35 S t)])
\end{array}
$$

where the Strouhal number $S t$ is given by $S t=f A_{\max } / U$ and in the case of the work chamber, $f=\omega /(2 \pi)$, and $A_{\text {max }}=r_{o}$ - note that the oscillation here is the transverse oscillation of the scroll wraps perpendicular to the flow direction. The mean velocity $U$ can be obtained from

$$
U=\frac{\dot{m}_{\text {total }}}{4 r_{o} h_{s} \rho_{m}}
$$

and an effective hydraulic diameter can be defined by

$$
D_{h}=\frac{4 r_{o} h_{s}}{\left(2 r_{o}+h_{s}\right)}
$$

The temperatures of the scroll wraps and the top and bottom plates are also needed in order to calculate the heat transfer rate. Jang and Jeong (2006) have experimentally shown that the temperatures of the metal scroll wraps are linear with the involute angle. In order to calculate the total amount of heat transfer to the gas/liquid mixture in the chambers, the calculation method from Halm (1997) is carried out. The order of magnitude of the heat transfer coefficient agrees with the CFD predictions of Zhu and Ooi (1997) of approximately $4 \mathrm{~kW} \mathrm{~m}^{-2} \mathrm{~K}^{-1}$. In practice, the performance of the model is not very sensitive to the heat transfer coefficient calculations for the scroll chambers. For instance in a scroll air compressor modified to be a scroll expander without oil flooding, an $800 \%$ increase in heat transfer coefficient results in a $3.7 \%$ decrease in mass flow rate (Lemort, 2008). When oil flooding is used, the impact of heat transfer is even less.

\section{Conservation Laws}

To obtain expressions for the derivatives of temperature and pressure of a given control volume, conservation of mass and energy must be expressed in differential form. The mixture properties can be uniquely defined using the independent variables temperature, pressure, and mixture liquid fraction. Conservation of mass, energy, and liquid mass for a control volume can be given as:

$$
\begin{gathered}
\frac{d m}{d t}=\sum\left[\dot{m}_{f}\right] \\
\frac{d E}{d t}=\dot{Q}+\dot{W}+\sum\left[\dot{m}_{f} h_{f}\right] \\
\frac{d m_{l}}{d t}=\sum\left[x_{l, f} \dot{m}_{f}\right]
\end{gathered}
$$

where the subscript $f$ corresponds to the given flow path. If these conservation laws are then converted into derivatives of temperature and pressure with respect to the crank angle $\theta$, a system of coupled differential equations results as seen in Eqn. 25 to 27

$$
\begin{aligned}
& \zeta_{1}=\sum_{f}\left[\frac{\dot{m}_{f}}{\omega}\left(\left(u-h_{f}\right)+\frac{d u}{d x_{l}}\left(x_{l, f}-x_{l}\right)\right)\right] \\
& \frac{d T}{d \theta}=-\frac{p \frac{d V}{d \theta}-\frac{\dot{Q}}{\omega}+\zeta_{1}}{\rho V \frac{d u}{d T}} \\
& \zeta_{2}=\sum_{f}\left[\frac{\dot{m}_{f}}{\omega}\left(\begin{array}{c}
\rho \frac{d u}{d T}+\frac{d \rho}{d T}\left(u-h_{f}\right) \\
+\left(\frac{d \rho}{d T} \frac{d u}{d x_{l}}-\frac{d u}{d T} \frac{d \rho}{d x_{l}}\right)\left(x_{l, f}-x_{l}\right)
\end{array}\right)\right] \\
& \frac{d p}{d \theta}=\frac{\frac{d \rho}{d T} p \frac{d V}{d \theta}-\frac{d \rho}{d T} \frac{\dot{Q}}{\omega}-\rho^{2} \frac{d u}{d T} \frac{d V}{d \theta}+\zeta_{2}}{\rho V\left(\frac{d u}{d T} \frac{d \rho}{d p}\right)} \\
& \frac{d x_{l}}{d \theta}=-\frac{\sum_{f}\left[\frac{\dot{m}_{f}}{\omega}\left(x_{l}-x_{l, f}\right)\right]}{\rho V}
\end{aligned}
$$

\section{Solution Method}

The temperature, pressure and oil mass fraction of the scroll machine chambers at the starting crank angle $(\theta=0)$ are initialized with guess values. Then for each iteration step, the mass flows are calculated between all of the chambers, as well as the instantaneous heat transfer between the scroll wraps and the mixture in the pockets at the $i$-th step. The temperature, pressure, and oil mass fraction at 
the $i+1$-th step in each chamber are obtained with the simple Euler method by simultaneously applying

$$
\begin{aligned}
& T_{i+1}=T_{i}+\left.\Delta \theta \frac{d T}{d \theta}\right|_{i} \\
& p_{i+1}=p_{i}+\left.\Delta \theta \frac{d p}{d \theta}\right|_{i} \\
& x_{l, i+1}=x_{l, i}+\left.\Delta \theta \frac{d x_{l}}{d \theta}\right|_{i}
\end{aligned}
$$

and $i$ goes from 1 to the number of steps, in this case, 2000. In order to carry out the calculations, and ensure that the inlet and outlet mass flow rates agree within $0.1 \%$, it was found that using 2000 forward Euler steps per revolution gives sufficient stability and accuracy.

Further work has been done on the scroll compressor model to implement an adaptive Runge-Kutta $4^{\text {th }} / 5^{\text {th }}$ order solver (Chapra and Canale, 2006) which was used for all the scroll compressor results presented here, and is described in Bell (2011).

\section{Model Closure}

In the absence of a mechanistic model for mechanical losses, it is possible to correlate the mechanical losses to the gas compression power and obtain an empirical relationship for the mechanical efficiency. This correlation is constructed by first running the model using input state points for which experimental data is available, with no mechanical losses or heat transfer. The residual between the model predicted shaft power and the experimental shaft power is then assumed to be due to mechanical losses.

A correlation of the form

$$
\dot{W}_{M L}=\omega \tau_{l o s s}
$$

is fit to the data for the compressor and expander and the loss coefficient $\tau_{\text {loss }}$ is obtained.

Once the pressure and temperature have been determined for one revolution, the energy balance for the lumped mass is obtained. The energy balance is a summation of the heat fluxes interacting with the lumped mass. Once the mechanical losses have been calculated, all of the mechanical losses are added to the lumped mass. Finally the temperature of the lumped mass is obtained by applying the secant solver method to the energy balance given by

$$
\dot{W}_{M L}+\sum\left[\dot{Q}\left(T_{\text {lump }}\right)\right]=0
$$

in order to obtain $T_{\text {lump }}$. After solving for $T_{\text {lump }}$, the outlet enthalpy from the scroll set can be determined by calculating the mean discharge enthalpy over one revolution from

$$
h_{\text {disc }}=\frac{\int_{\text {discharge }} \dot{m}_{f} h_{f}}{\int_{\text {discharge }} \dot{m}_{f}}
$$

through the use of a numerical integration scheme. Solving for the temperature as a function of scroll set discharge enthalpy and pressure gives the temperature at the outlet of the scroll set. Further heat transfer in the discharge region will heat or cool the discharging flow, and will result in discharge temperature $T_{d}$ at the outlet of the scroll machine. In the case of overexpansion or undercompression there will be back flow as the work chamber opens to the discharge pressure. The shaft power of the machine is then given by

$$
\dot{W}_{\text {shaft }}=\left(\dot{m}_{l}+\dot{m}_{g}\right)\left(h_{m}\left(T_{d}, p_{d}\right)-h_{s u c t}\right)-\dot{Q}_{a m b}
$$

where the heat transfer $\dot{Q}_{a m b}$ is taken to be positive if heat is into the scroll machine, and the enthalpies are based on mixture properties from Section 3 .

\section{Results}

While model validation and experimental results are available in the companion papers, a few results are presented here. Figures 12 and 13 show the scroll compressor pressures and temperatures over one revolution with a significant amount of liquid flooding. The working gas is nitrogen, and the flooding liquid is Zerol oil. A few features should be noted, especially the relatively large suction and discharge pressure drops and the maladjustment of the current machines' volumetric ratios for the imposed pressure ratio. In fact, the ideal volume ratio (for fixed suction and discharge pressures) changes as one changes the oil mass fraction since the effective fluid properties change with liquid flooding. In particular, the effective ratio of specific heats changes with liquid flooding. The analysis of the optimal volume ratio is developed in the companion paper. Clearly, the off-the-shelf scroll compressor is not optimal for the application but exhibits fairly good performance. Figure 13 demonstrates the benefit of liquid flooding in reducing the discharge temperature of the compression process. If pure nitrogen were to be compressed in the scroll compressor, from an inlet state of $400 \mathrm{kPa}$ and $300 \mathrm{~K}$ to an outlet pressure of $1200 \mathrm{kPa}$, the model predicts a discharge temperature of $480 \mathrm{~K}$ without flooding, while the flooded compressor has a discharge temperature of $348.6 \mathrm{~K}$.

In the expander, similar trends are seen in Figures 14 and 15. The volume ratio of the expander is also too small for the imposed pressure ratio, and as a result, the expander experiences under-expansion losses because the working process does not expand the fluid all the way to the discharge pressure.

\section{Conclusions}

Detailed flooded scroll compressor and scroll expander models have been developed. The scroll machine model consists of the following sub-models: 


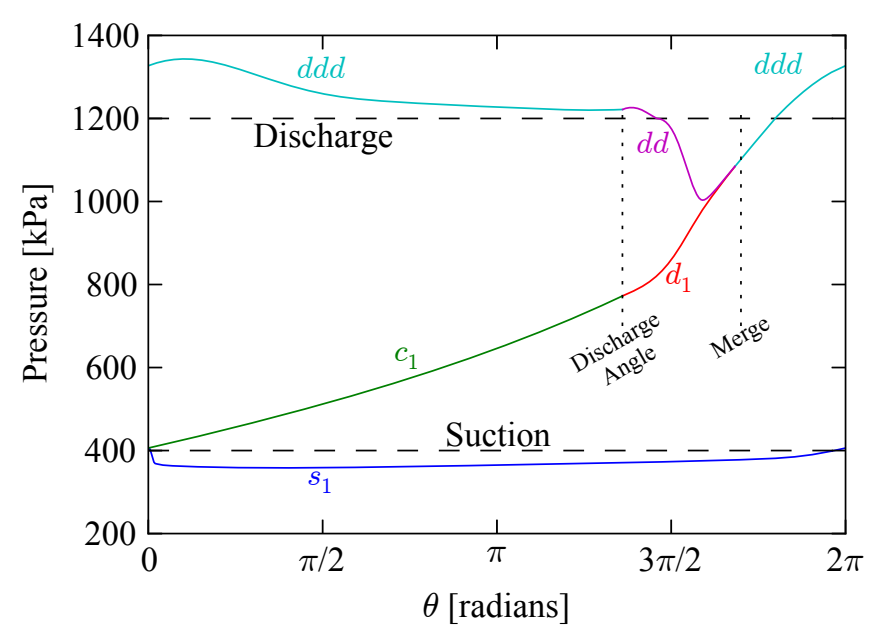

Figure 12: Pressure versus crank angle for flooded compressor $\left(p_{s}=400 \mathrm{kPa}, p_{d}=1200 \mathrm{kPa}, T_{s}=300 \mathrm{~K}, x_{l}=0.5, \mathrm{~N}=3500 \mathrm{rpm}\right)$

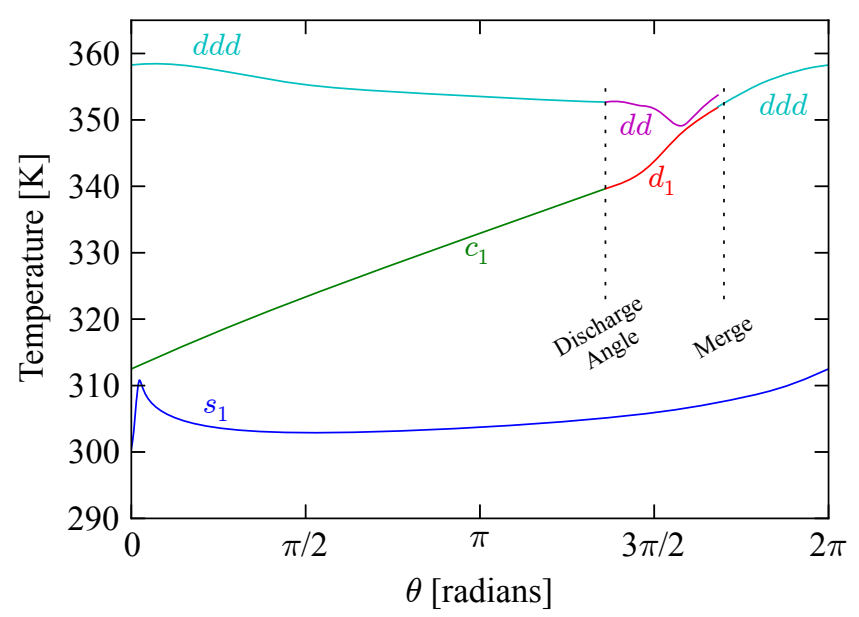

Figure 13: Temperature versus crank angle for flooded compressor $\left(p_{s}=400 \mathrm{kPa}, p_{d}=1200 \mathrm{kPa}, T_{s}=300 \mathrm{~K}, x_{l}=0.5, \mathrm{~N}=3500 \mathrm{rpm}\right)$

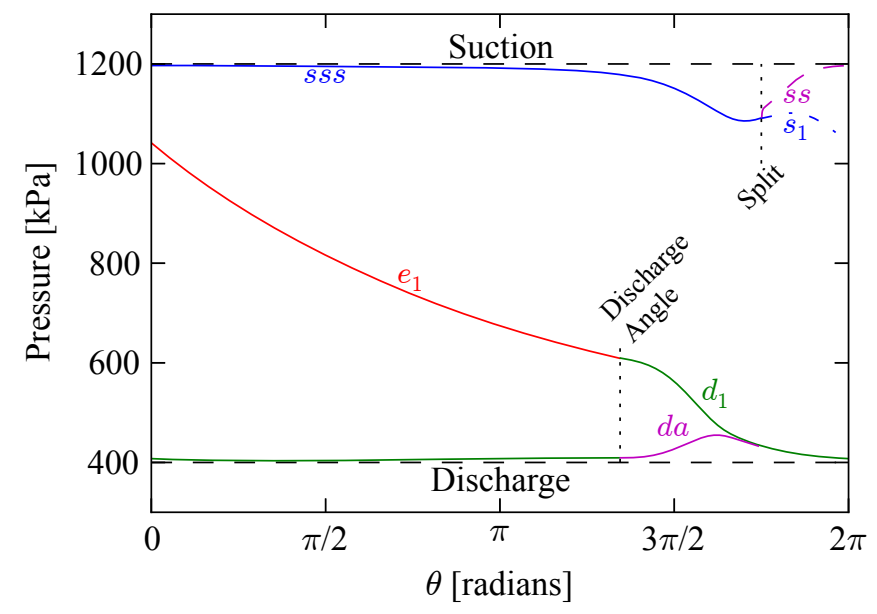

Figure 14: Pressure versus crank angle for flooded expander $\left(p_{s}=1200 \mathrm{kPa}, p_{d}=400 \mathrm{kPa}, T_{s}=300 \mathrm{~K}, x_{l}=0.5, \mathrm{~N}=1736 \mathrm{rpm}\right)$

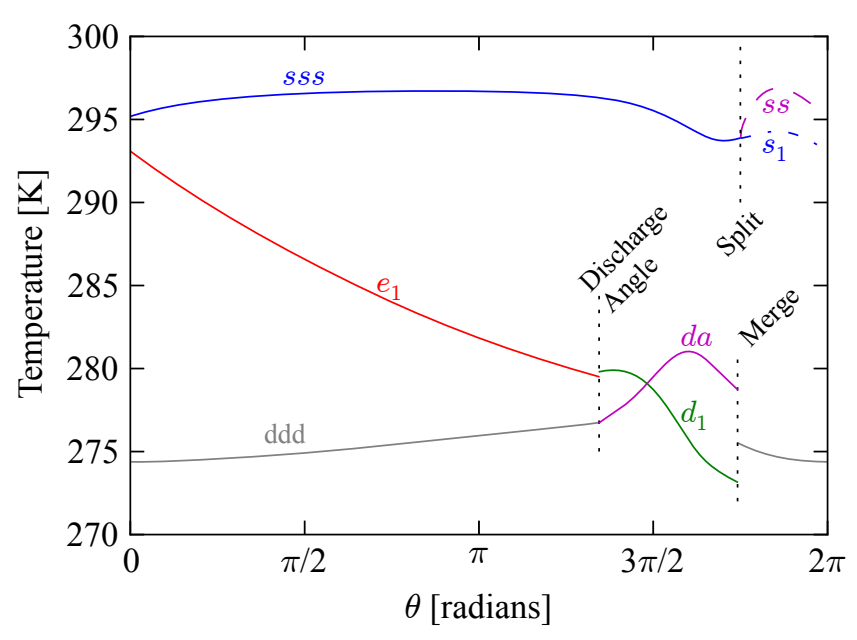

Figure 15: Temperature versus crank angle for flooded expander $\left(p_{s}=1200 \mathrm{kPa}, p_{d}=400 \mathrm{kPa}, T_{s}=300 \mathrm{~K}, x_{l}=0.5, \mathrm{~N}=1736 \mathrm{rpm}\right)$

- A volume calculation routine which permits calculations of scroll machine chamber volumes as a function of the crank angle

- Mass flow models to calculate the instantaneous mass flow rates between scroll chambers

- An adjusted heat transfer coefficient model suitable for calculating the heat transfer between the gas-oil mixture and the scroll wraps

- A differential equation solver that allows the temperature and pressure in the control volumes to be calculated as a function of crank angle

- An overall solver function that obtains the temperatures of the lumped masses and calculates the relevant performance parameters

Due to the mechanistic construction of the scroll machine model it is therefore possible to use the model to investigate design changes on the performance of the scroll machines with liquid flooding. The companion papers validate the model presented here and use the model presented here to optimize scroll compressor performance with liquid flooding.

\section{References}

Bein, T. W., Hamilton, J. F., 1982. Computer modeling of an oil flooded single screw air compressor. In: 1982 International Compressor Engineering Conference at Purdue University. pp. 127134.

Bell, I., 2011. Theoretical and Experimental Analysis of Liquid Flooded Compression in Scroll Compressors. Ph.D. thesis, Purdue University.

URL http://docs.lib.purdue.edu/herrick/2/

Bell, I., Groll, E., Braun, J., King, G., 2011a. Liquid-Flooded Compression and Expansion in Scroll Machines - Part III: Optimization of Scroll Compressor Geometry. Int. J. Refrig. Submitted for Publication. 
Bell, I., Lemort, V., Groll, E., Braun, J., King, G., 2011b. LiquidFlooded Compression and Expansion in Scroll Machines - Part II: Experimental Testing and Model Validation. Int. J. Refrig. Submitted for Publication.

Blaise, J., Dutto, T., 1988. Influence of oil injection and pressure ratio on single screw performances at high temperatures. In: 1988 International Compressor Engineering Conference at Purdue University. pp. 338-345.

Blunier, B., Cirrincione, G., Hervé, Y., Miraoui, A., 2009. A new analytical and dynamical model of a scroll compressor with experimental validation. International Journal of Refrigeration 32, 874-891.

Blunier, B., Cirrincione, G., Mairaoui, A., 2006. Novel Geometrical Model of Scroll Compressors for the Analytical description of the chamber volumes. In: 2006 International Compressor Engineering Conference at Purdue University. No. C074.

Bush, J. W., Beagle, W. P., 1992. Derivation of a General Relation Governing the Conjugacy of Scroll Profiles. In: 1992 International Compressor Engineering Conference at Purdue University. pp. 1079-1087.

Bush, J. W., Beagle, W. P., Housman, M. E., 1994. Maximizing Scroll Compressor Displacement Using Generalized Wrap Geometry. In: 1994 International Compressor Engineering Conference at Purdue University. pp. 205-210.

Chapra, S. C., Canale, R. P., 2006. Numerical Methods for Engineers. McGraw-Hill.

Chen, Y., Braun, J., Groll, E., 2004. Modeling of Hermetic Scroll Compressors: Model Development. HVAC\&R Research 10, 129152.

Chen, Y., Halm, N., Groll, E., Braun, J., 2002. Mathematical Modeling of Scroll Compressor. Part I- Compression Process Modeling. International Journal of Refrigeration 25, 731-750.

Chisholm, D., 1983. Two-Phase flow in pipelines and heat exchangers. George Goodwin, London.

Creux, L., 1905. Rotary Engine - US Patent No. 801182.

Fujiwara, M., Osada, Y., 1995. Performance analysis of an oilinjected screw compressor and its application. Int. J. Refrig. 18, 220-227.

Halm, N., 1997. Mathematical Modeling of Scroll Compressors. Master's thesis, Purdue University.

Hiwata, A., Iida, N., Futagami, Y., Sawai, K., Ishii, N., 2002. Performance investigation with oil-injection to compression chambers on $\mathrm{CO}_{2}$-scroll compressor. In: 2002 Purdue Compressor Conference. No. C18-4.

Ishii, N., Bird, K., Sano, K., Oono, M., Iwamura, S., Otokura, T., 1996. Refrigerant Leakage Flow Evaluation for scroll compressors. In: 1996 Compressor Conference at Purdue University.

Ishii, N., Oku, T., Anami, K., Knisely, C. W., Sawai, K., Morimoto, T., Fujiuchi, K., 2008. Effects of Surface Roughness upon Gas Leakage Flow through small clearances in $\mathrm{CO}_{2}$ scroll compressors. In: 2008 International Compressor Engineering Conference at Purdue University.

Jang, K., Jeong, S., 2006. Experimental investigation on convective heat transfer mechanism in a scroll compressor. Int. J. Refrig. 29, 744-753.

Kemp, G., Elwood, L., Groll, E. A., 2010. Evaluation of a Prototype Rotating Spool Compressor in Liquid Flooded Operation. In: 20th International Compressor Engineering Conference at Purdue University.

Lemort, V., 2008. Contribution to the characterization of scroll machines in compressor and expander modes. Ph.D. thesis, University of Liège.

Li, H., Jin, L., 2004. Design Optimization of an oil-flooded Refrigeration single-screw compressor. In: 2004 International Compressor Engineering Conference at Purdue University. No. C077.

McAdams, W., Wood, W., Bryan, R., 1942. Vaporization inside Horizontal Tubes - II: Benzene-oil mixtures. Transactions ASME 64, 193.

Morris, S., 1991. Compressible gas-liquid flow through pipeline restrictions. Chem. Eng. Process. 30, 39-44.

Sakuda, A., Sawai, K., Iida, N., Hiwata, A., Morimoto, T., Ishii, N.,
2001. Performance improvement of scroll compressor with new sealing-oil supply mechanism. In: International Conference on Compressors and their Systems. No. C591/019.

Singh, P. J., Patel, G. C., 1984. A generalized performance computer program for oil flooded twin-screw compressors. In: 1984 International Compressor Engineering Conference at Purdue University. pp. $544-553$.

Stosic, N., Kovacevic, A., Hanjalic, K., Milutinovic, L., 1988. Mathematical modelling of the oil influence upon the working cycle of screw compressors. In: 1988 International Compressor Engineering Conference at Purdue University. pp. 354-361.

Stosic, N., Milutinovic, L., Hanjalic, K., Kovacevic, A., 1990. Experimental investigation of the influence of oil injection upon the screw compressor working process. In: 1990 International Compressor Engineering Conference at Purdue University. pp. 34-43.

Tagri, N., Jayaraman, R., 1962. Heat transfer studies on a spiral plate heat exchanger. Trans. Inst. Chem. Eng. 40, 161-168.

Tang, Y., Fleming, J. S., 1992. Simulation of the working process of an oil flooded helical screw compressor with liquid refrigerant injection. In: 1992 International Compressor Engineering Conference at Purdue University. pp. 213-220.

Wang, B., Li, X., Shi, W., 2005. A general geometrical model of scroll compressors based on discretional initial angles of involute. Int. J. Refrig. 28, 958-966.

Wu, H., Xing, Z., Shu, P., 2004. Theoretical and experimental study on indicator diagram of twin screw refrigeration compressor. Int. J. Refrig. 27, 331-338.

Wu, J., Jin, G., 1988. The computer simulation of oil-flooded single screw compressors. In: 1988 International Compressor Engineering Conference at Purdue University. pp. 362-368.

Yanagisawa, T., Cheng, M. C., Fukuta, M., Shimizu, T., 1990. Optimum operating pressure ratio for scroll compressor. In: 1990 International Compressor Engineering Conference at Purdue University. pp. 425-433.

Zhu, J., Ooi, K., 1997. Prediction of Flow and Heat Transfer Within a Compressor Working Chamber. In: Proceedings of the ASME Advanced Energy Systems Division. pp. 463-468. 


\section{Nomenclature}

A Area $\left(\mathrm{m}^{2}\right)$

C Velocity $\left(\mathrm{m} \mathrm{s}^{-1}\right)$

$C_{d} \quad$ Discharge Coefficient

$C_{\text {ratio }} \quad$ Capacitance Rate Ratio

$c_{p} \quad$ Specific Heat $\left(\mathrm{kJ} \mathrm{kg}^{-1} \mathrm{~K}^{-1}\right)$

$D_{h} \quad$ Hydraulic Diameter (m)

E Energy (kJ)

$G \quad$ Mass Flux $\left(\mathrm{kg} \mathrm{m}^{-2} \mathrm{~s}^{-1}\right)$

$h \quad$ Specific Enthalpy $\left(\mathrm{kJ} \mathrm{kg}^{-1}\right)$

$h_{c} \quad$ Local Heat Transfer Coefficient $\left(\mathrm{kW} \mathrm{m}^{-2} \mathrm{~K}^{-1}\right)$

$h_{s} \quad$ Scroll Height $(\mathrm{m})$

$k \quad$ Thermal Conductivity $\left(\mathrm{kW} \mathrm{m}^{-1} \mathrm{~K}^{-1}\right)$

$K \quad$ Slip ratio

$m$ Mass (kg)

$\dot{m} \quad$ Mass Flow $\left(\mathrm{kg} \mathrm{s}^{-1}\right)$

$p \quad$ Pressure $(\mathrm{kPa})$

$P \quad$ Perimeter

Pr Prandtl Number

$r_{b}$

$r_{o}$

$\mathrm{Re}$

$s$

Flow Correction Factor

Specific Volume $\left(\mathrm{m}^{3} \mathrm{~kg}^{-1}\right)$

Void Fraction

Gap width (m)

Involute Angle (rad)

Entrainment Fraction

Density $\left(\mathrm{kg} \mathrm{m}^{-3}\right)$

Ratio Down/Upstream Area

Torque (N m)

Viscosity (Pa s)

Rotational Speed $\left(\operatorname{rad~s}^{-1}\right)$

\section{Subscripts}

$\begin{array}{ll}C V & \text { For the given control volume } \\ d i s c & \text { Discharge } \\ e & \text { Effective } \\ f & \text { For the flow path } \\ f & \text { Flank } \\ g & \text { Gas } \\ i & \text { Iteration Index } \\ i 0 & \text { Inner Involute Initial } \\ i e & \text { Inner Involute Ending } \\ i s & \text { Inner Involute Starting } \\ l & \text { Liquid } \\ \text { loss } & \text { Loss } \\ m & \text { Mixture } \\ o 0 & \text { Outer Involute Initial } \\ \text { oe } & \text { Outer Involute Ending } \\ \text { os } & \text { Outer Involute Starting } \\ r & \text { Radial } \\ \text { shell } & \text { Shell Lump Mass } \\ \text { scroll } & \text { Scroll Lump Mass }\end{array}$

\section{Chambers}

$c_{1}$

$e_{1}$

$d_{1}$

$d a$

$d d$

$d d d$

$s_{1}$

$s a$

$s s$

$s s s$
Compressor compression chamber Expander expansion chamber Discharge chamber Expander discharge area plenum Compressor central discharge chamber Compressor merged discharge chamber Compressor suction chamber Compressor suction area plenum Expander central suction chamber Expander merged suction chamber 